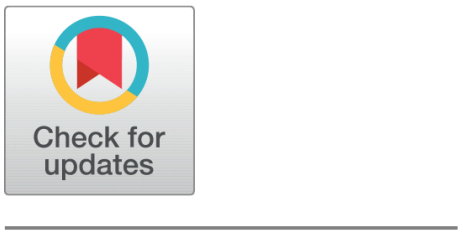

OPEN ACCESS

Received: 07.11.2020

Accepted: 06.12.2020

Published: 14.04.2021

Citation: Xu W, Itagi R Kumar , Thaiyar M Srinivasan (2021) Evaluation of Impact of Ethics of Yoga in the Psychological Health of College Students: A Randomized Control Trial. Indian Journal of Science and Technology 14(12): 999-1005. https://doi.org/ 10.17485/IJST/V14i12.2001

* Corresponding author.

Tel: +919380403747

estherxu@hotmail.com

Funding: None

Competing Interests: None

Copyright: (c) $2021 \mathrm{Xu}$ et al. This is an open access article distributed under the terms of the Creative Commons Attribution License, which permits unrestricted use, distribution, and reproduction in any medium, provided the original author and source are credited.

Published By Indian Society for Education and Environment (iSee)

ISSN

Print: 0974-6846

Electronic: 0974-5645

\section{Evaluation of Impact of Ethics of Yoga in the Psychological Health of College Students: A Randomized Control Trial}

\author{
Wen $\mathrm{Xu}^{1 *}$, Itagi R Kumar², Thaiyar M Srinivasan ${ }^{3}$ \\ 1 PhD scholar, Division of Yoga and Physical Sciences, S-VYASA Deemed-to-be-University, No. \\ 19, Eknath Bhavan, Gavipuram Circle, Kempegowdanagar, Bengaluru, 560019, Karnataka, \\ India. Tel.: +919380403747 \\ 2 Associate Professor, Division of Yoga and Physical Sciences, S-VYASA Deemed-to-be- \\ University, No. 19, Eknath Bhavan, Gavipuram Circle, Kempegowdanagar, Bengaluru, 560019, \\ Karnataka, India \\ 3 Professor, Division of Yoga and Physical Sciences, S-VYASA Deemed-to-be-University, No. \\ 19, Eknath Bhavan, Gavipuram Circle, Kempegowdanagar, Bengaluru, 560019, Karnataka, \\ India
}

\section{Abstract}

Background/Objectives: The foundational ethical principles of yoga have not been of focus and not widely known. This study was to evaluate the yoga ethics that could reduce the level of stress in college students. Methods/Statistical analysis :A randomized control trial was conducted. One hundred participants were randomly assigned to control group and experiment group with a duration of three months intervention and one month follow-up. The outcome measures of stress level were assessed through Bio-Well instrument. A parametric independent sample t-test for the between-group analyses and paired sample t-test for within-group analysis compared the means of two groups. Findings: There was a statistically significant reduction in the stress after the intervention $(p<0.001)$ and follow up $(p=0.035)$ between the group comparisons. The within-group comparisons showed high reduced in the level of stress after the intervention $(p<0.001)$ and follow-up $(p<0.01)$. Novelty: The current study provides preliminary evidence that the practice of ethical principles of Yama and Niyama effectively reduces the stress and may improve psychological health and well-being.

Keywords: Yoga ethics; Yama; Niyama; Stress; Psychological wellbeing;

BioWell

\section{Introduction}

Emotional pressures are common among college students, such disorders were first identified in their early 20s, which indicated that the high-risk period for adolescent onset persisted into young adulthood ${ }^{(1)}$. Increasingly, epidemiological studies consistently find the rising prevalence rate of mental disorders among college students around the world, with majority of freshman reported experiencing medium to high level of emotional pressures ${ }^{(2)}$. However, only a small minority $(16.4 \%)$ of students with 12 -month mental disorders received adequate treatment due to the high prevalence 
and insufficient resource services ${ }^{(3)}$. The common mental problems in this major life transition period is not only associated with lower academic performance ${ }^{(4)}$ but also with college attrition, emotional stress and anxiety, suicidal thoughts, behavioural and substance addictions as well as general health ${ }^{(2,3,5)}$. It is important to resolve mental disorders early and develop feasible, efficient and cost-effective stress interventions to prevent and reduce emotional pressures in college students.

Many reviews show yoga including meditation and mindfulness interventions demonstrate a reduction in perceived stress, depression and anxiety in youth during education ${ }^{(6-10)}$. According to previous findings, yoga is one of the interventions increasingly popular with tertiary education students, and positive outcomes were reported in most studies. The studies have shown yoga programs facilitated multitude aspects of psychological health and well-being which covered academic performance stress $^{(11,12)}$, emotion regulation and different aspects of psychological well-being such as quality of life, perceived stress and selfregulation, mindfulness, self-compassion ${ }^{(13-16)}$ as well as cognitive functions and creative ability ${ }^{(17-20)}$. Most studies on yoga focus on the combination of postures, breathing exercises and meditation components. However, the ethical principles of $y o g a$ enunciated in Yama and Niyama are not well known and are not usually presented to students of yoga.

The traditional ancient science of yoga includes physical, mental and spiritual practices to uplifting mankind. India's great sage Patañjali outlined the eight fold path of yoga in his renowned Yoga Sütra ${ }^{(21)}$. Among aforesaid eight steps (or limbs), the first two fundamental ethical disciplines of yoga path include five Yamās (proscriptive moralities) and Niyamās (prescriptive rules) respectively [Table 1]. Thus, the ethics propound in yoga are seen as actions and embodied tremendous positive value that helps to calm down the restless mind, improve consciousness, self-regulate emotions and prosocial behaviours ${ }^{(22)}$. Moreover, a few empirical studies evaluated the effectiveness of separate limbs of yoga (postures, breathing exercises, and meditation) on stress reduction on healthy college students ${ }^{(23-25)}$, and showed the beneficial effects that vary with length of the intervention. However, what has been neglected in this field, and until now is the potential effects of Yama and Niyama on psychological and emotional well-being have not been investigated.

Table 1. Yama and Niyama intervention for three month

\begin{tabular}{|c|c|c|c|}
\hline Name of the practice & Duration & Content information & \\
\hline \multirow{14}{*}{$\begin{array}{l}\text { Yama-Niyama } \\
\text { lecture }\end{array}$} & \multirow{14}{*}{$15 \mathrm{~min}$} & \multicolumn{2}{|l|}{ 1. Explain the concept of each Yama and Niyama } \\
\hline & & Five Yamās: & Five Niyamās: \\
\hline & & Ahimsā - non-violence & Śauca - cleanliness, purity \\
\hline & & Satya - truthfulness & Santoṣa - contentment \\
\hline & & Asteya - non-stealing & Tapas - austerity \\
\hline & & Brahmacharya - continence & Svādhyāya - self-study \\
\hline & & Aparigraha - non- covetousness & İśvara praṇidhāna - surrender to God \\
\hline & & \multicolumn{2}{|l|}{ 2. How to apply each discipline in daily life } \\
\hline & & $\begin{array}{l}\text { Ahiminā, e.g., not to hurt any creatures: human } \\
\text { beings, animals, plants. }\end{array}$ & $\begin{array}{l}\text { Sauca, e.g., cleanness of body and purity of } \\
\text { mind. }\end{array}$ \\
\hline & & $\begin{array}{l}\text { Satya,e.g., by honouring the principle of truth in } \\
\text { thoughts, speech, and actions. }\end{array}$ & Santoșa, e.g., simple living, high thinking \\
\hline & & $\begin{array}{l}\text { Asteya, e.g., develop a consciousness of abun- } \\
\text { dance }\end{array}$ & Tapas, e.g., austerity of the body, speech, mind \\
\hline & & $\begin{array}{l}\text { Brahmacharya, e.g., follow the middle path, be } \\
\text { balanced and moderate in all things }\end{array}$ & $\begin{array}{l}\text { Svādhyāya, e.g., reading scriptures with } \\
\text { understanding its meaning and assimilating it } \\
\text { into life. }\end{array}$ \\
\hline & & $\begin{array}{l}\text { Aparigraha, e.g., purify the heart of envy and } \\
\text { jealousy }\end{array}$ & $\begin{array}{l}\text { İvara pranidhāna, e.g., cultivate an increased } \\
\text { trust, faith and devotion in God }\end{array}$ \\
\hline & & \multicolumn{2}{|c|}{$\begin{array}{l}\text { 3. Studying 'how to live' teachings through the topic 'Ridding the consciousness of worry' and 'The } \\
\text { law of success', with a discussion how these teachings manifest the Yama and Niyama disciplines. }\end{array}$} \\
\hline Japa writing & $20 \mathrm{~min}$ & \multicolumn{2}{|c|}{ Writing two rounds of the selected śloka from Bhagavad Gītā, chapter 16, verse 1-3. } \\
\hline Introspection & $5 \mathrm{~min}$ & \multicolumn{2}{|c|}{$\begin{array}{l}\text { According to each YN lecture theme, mentally review the different circumstances that one passes } \\
\text { through. Recall to mind the particular aspects of spiritual living, and ask oneself: "How did I do?", } \\
\text { use affirmations to impress on hearts and minds the qualities that one is focusing on. }\end{array}$} \\
\hline Counselling & $5 \mathrm{~min}$ & \multicolumn{2}{|c|}{ Clearing of the questions/doubts in the class or related to life problems. } \\
\hline
\end{tabular}

In addition to access stress score with a combination of questionnaires or scales in most yoga experiments, we observed Electro Photonic Imaging (EPI) is another direct and efficacious instrument to evaluate the stress level ${ }^{(26)}$. Several studies have demonstrated that EPI technology measures the level of stress in yoga practice ${ }^{(27-29)}$. Hence, in the current study, aimed to evaluate the stress level using Bio-Well device, and tested the hypothesis that practice of Yama and Niyama may have potential effects in prevention of stress-induced psychological disorders among college students. 


\section{Materials and Methods}

The participants are from a public college in the north-eastern part of India. One hundred college students (71\% male, $29 \%$ female) age ranging from 18 to 26 years $(\mathrm{M} \pm \mathrm{SD}=19.45 \pm 1.20)$ who meet the inclusion criteria were recruited and randomly divided into control ( $\mathrm{n}=50,78 \%$ male, $22 \%$ female) and Yama and Niyama $(\mathrm{YN})$ group ( $\mathrm{n}=50,64 \%$ male, 36\% female). All participants have graduated from high school. Daily record sheet of the ethical disciplines given to YN group was obtained from students with the weekly records to understand their attitude and experience through Yama and Niyama practice. All the students who are of age between 18-26 years, all novice to yoga practice and knowing basic English were included in the study. Students having psychophysical problems, missing fingers and/or have practiced yoga were excluded. The assessments were taken three times for all the students (baseline levels, at the end of three months of practice and one-month follow-up). The study protocol was reviewed and approved by the Institutional Ethics Committee and informed consent signed by all the participants.

\subsection{Intervention}

The YN group given intervention of six sessions in each week for three months, 45 minutes in each session. The intervention comprised of YN lectures, Japa writing, introspection, counselling [Table 1]. The YN lectures are based on Patañjali's Yoga Sütras and inspired by the teaching of Svāmī Paramahamsa Yogānanda, who emphasize ideal education for youth is not only aimed at the development of body and intellect but also the need to cultivate the values of ethics and spirituality, through which one could attain happiness ${ }^{(30)}$. Yet such an approach is lacking in the formal curriculum in the modern career-oriented education. This ideal education of 'how to live' teachings in his school attained remarkable success. The control group were arranged to take a regular course for 45 minutes, for the same time duration as the experimental group. Attendance was taken by their course teacher. In the follow-up, the YN group were assembled for one session for each week to review and discuss the difficulty they face in $\mathrm{YN}$ practice. The control group followed their college routine.

\subsection{Outcome measure}

The stress level was assessed by Electron Photonic Imaging (EPI) technology known as Bio-Well which has been developed over more than 25 years by Russia scientist Dr Konstantin Korotkov and his team. The Bio-Well portable device is a safe, effective and non-invasive tool measuring the bio-energy of a person based on the theory of meridians of acupuncture. Finger pads of each of 10 fingers are placed on a glass plate of the EPI camera, and a burst of high voltage, short pulse (10 KV, 3 millisecond) is applied to the finger. This elicits photon emission from fingertips generating EPI images. The readings are processed through Bio-Well software $^{(31)}$. The EPI readings reflect the state of physical, mental, emotional and spiritual health of the person. Emotional pressure which characterizes stress levels has a 0 to 10 scale score [Figures 1 and 2 ], the lower the score reflects the state of inner peace, while the higher scores reveal emotional imbalance - anxiety, as in a stressful situation ${ }^{(26)}$. The scale score has the following interpretation:

0-1: complete inner peace, it may be the states of deep meditation.

$0-2$ : very calm state and relaxed.

2-3: normal calm state, the score 2.5 above that may associate with anxiety but not permanent.

3-4: The state of permanent anxiety, inability to relax.

4-10: The continually stress state with different degree.

Three assessments of bioenergy data collection were conducted at the same time $(8: 30 \mathrm{am}-11: 30 \mathrm{am})$, in the same room, and the participants were asked to report with an empty stomach for 3 hours before collecting the data.

EMOTIONAL PRESSURE: Stress

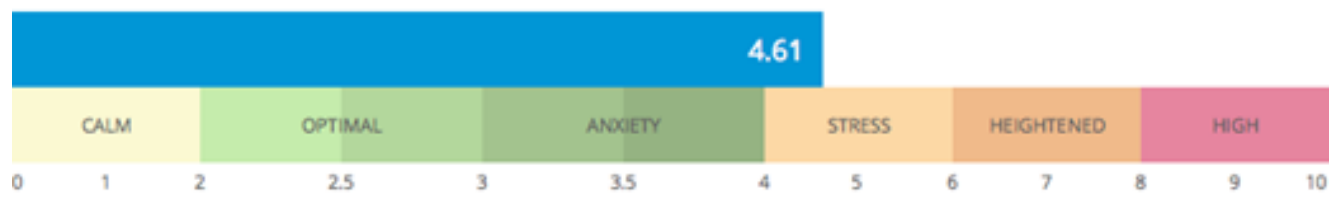

Fig 1. The emotional pressure before the intervention

Note: Figure 1 is an example from an individual's stress level changes before and after the intervention 
EMOTIONAL PRESSURE: Optimal

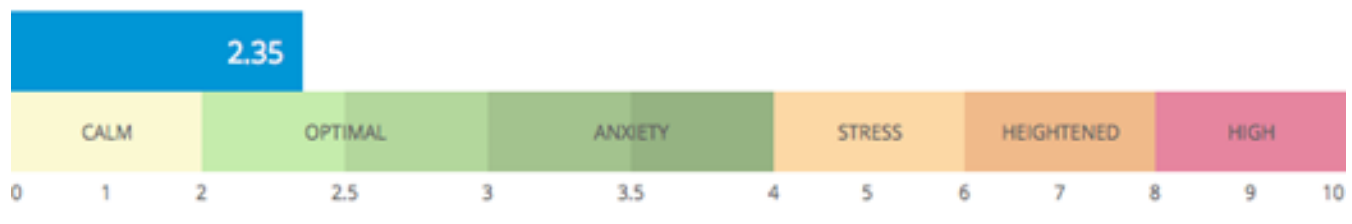

Fig 2. The emotional pressure after the intervention

Note: Figure 2 is an example from an individual's stress level changes before and after the intervention

\subsection{Data analysis}

The data analysis was performed using the Statistical Package for Social Science (SPSS) Version 23. Effect Size Calculator was used for Cohen's d effect size. A parametric independent sample t-test for the between-group analyses and paired sample t-test for within-group analysis compared the means of two groups. For all analysis, significance was set as $\mathrm{p}<0.05$.

\section{Results and Discussion}

Of the 50 YN participants, 40 participants completed the intervention and gave Bio-Well data before and after the course; 10 participants dropped out for not following the requirements of attendance above $80 \%$. Of the 50 control participants, 45 completed both sets; 5 participants dropped out due to insufficient attendance. In all, 31 participants in both groups completed one-month follow-up; 9 and 14 participants dropped out in the $\mathrm{YN}$ and control group due to missing the date of data collection. The current study showed the baseline stress level was not significantly different between two groups $(p=0.186, d=0.27)$. The between-group comparisons showed the results were clearly reduced after invention $(\mathrm{p}<0.001, \mathrm{~d}=0.84)$ and follow up ( $\mathrm{p}=0.035$, $\mathrm{d}=0.55)$. The outcome for stress level between the groups are shown in Table 2.

Table 2. Independent sample t-test after intervention and follow-up.

\begin{tabular}{lllllll}
\hline Variables & Timing & Control group $\mathrm{M} \pm \mathrm{SD}$ & YN group $\mathrm{M} \pm \mathrm{SD}$ & $\mathrm{t}$ value & Cohen’s d & $\mathrm{p}$ value \\
\hline \multirow{2}{*}{ Emotional } & pretest & $2.78 \pm 0.47$ & $2.91 \pm 0.54$ & -1.33 & 0.27 & 0.186 \\
pressure & posttest & $2.95 \pm 0.50$ & $2.62 \pm 0.21$ & 3.81 & 0.84 & $0.001^{* * *}$ \\
& follow-up & $2.81 \pm 0.35$ & $2.65 \pm 0.22$ & 2.15 & 0.55 & $0.035^{*}$ \\
\hline
\end{tabular}

Note: ${ }^{*} \mathrm{p}<0.05,{ }^{* *} \mathrm{p}<0.01,{ }^{* *} \mathrm{p}<0.001$, effect size: 0.2 is considered small, 0.5 is medium and 0.8 is large

The within-group comparisons and the effect size showed a significantly reduced scores of stress level after the intervention $(\mathrm{p}<0.001, \mathrm{~d}=0.69)$ and follow-up $(\mathrm{p}<0.01, \mathrm{~d}=0.49)$. The outcomes are shown in Table 3.

Table 3. Paired sample t-test after intervention and follow-up

\begin{tabular}{llllll}
\hline \multicolumn{5}{c}{ During intervention period } \\
\hline Variables & Pretest $(\mathrm{M} \pm \mathrm{SD})$ & Posttest $(\mathrm{M} \pm \mathrm{SD})$ & $\mathrm{t}$ value & Cohen's d & $\mathrm{p}$ value \\
\hline Emotional pressure & $3.01 \pm 0.55$ & $2.62 \pm 0.21$ & 4.35 & 0.69 & $0.001^{* * *}$ \\
\hline Emotional pressure & $2.93 \pm 0.55$ & Follow-up & & \\
\hline
\end{tabular}

Note: ${ }^{*} \mathrm{p}<0.05,{ }^{* *} \mathrm{p}<0.01,{ }^{* * *} \mathrm{p}<0.001$, effect size: 0.2 is considered small, 0.5 is medium and 0.8 is large

In the current study, we aimed to evaluate the effect of practice of ethical principles of Yama and Niyama (YN) on stress reduction in college students. We found that $\mathrm{YN}$ intervention resulted in significantly decreased stress level compared to the control group in both during experiment and follow-up. The finding demonstrated the feasibility and the value of yoga ethical principles practice in the academic environment which aligned with the hypothesis that participation in the YN program significantly decreased stress. This study also provided initial experiments of Yama and Niyama could be self-care strategies among college groups. With regularity of practice over a duration of time and set into the daily life, it can have a significant positive impact on stress reduction, even more, have a profound impact in an individual's present and future life. 
Our findings agree with previous studies that the effects of separate limbs of yoga may decrease stress level ${ }^{(23,24)}$. Themagnitude of the effect size in the current study was medium to large, while effect sizes found in the previous study with short duration have typically been small to medium ${ }^{(9,15,32)}$, which indicated long term of intervention may enhance the more positive beneficial effects over time. Multiple studies, through different yoga approaches and durations, propose that the common biological mechanisms for yoga practice reduced the stress level by decreasing the sympathetic activity and activating the parasympathetic activity ${ }^{(12,33,34)}$, and the increased cortisol level mitigates through yoga practice in the context of stressors ${ }^{(6,35)}$. Interestingly, Gard et al ${ }^{(32)}$ suggesting a framework showed the potential self-regulatory emotional mechanisms of the specific components of yoga practice, including ethical precepts that seem to improve the self-regulation by top-down regulatory processing associated with high-level brain networks (moral cognition network), while inhibiting emotional reactivity and negative appraisal. Moreover, previous evidence-based findings indicate the psychological mechanisms, that reduction in perceived stress improved in subjective well-being (quality of life and self-satisfaction), self-compassion, mindfulness, cognitive abilities ${ }^{(13-16,36)}$. The earlier western experimental studies have reported more female participants, while the present study has more male participants. Although only limited literature on the ethics of yoga is available, we assume Yama and Niyama practice may share similar mechanisms, the results of reduced the stress level may be associated with improved additional varying psychological well-being outcomes. We need further evaluation in future studies.

The stress and anxiety one often feel are because of violating Yama and Niyama ${ }^{(37)}$. The source of stress among college students are mainly from the financial situation, health, love life, relationship with family and friends, academic performance, problems experienced by loved ones ${ }^{(38)}$. In this study, the systematic curriculum of yoga ethics may provide effective cognitive ability to cope with these stressors. We gave lectures and practical focus on the theme of Yama and Niyama. For example, we explain each discipline through the lectures and review the points which were covered and discus how to apply them into the varying circumstance of life. Especially, the mindful technique of Japa writing (Bhagavad Gìtā, XVI:1-3) along with daily introspection might rewire the brain and keep these spiritual principles at the forefront of the mind. This argument was based on the previous studies on emotion regulation related to moral development and neuroimaging on moral cognition ${ }^{(39,40)}$.

We summarize general observations from the daily records and feedbacks from students and teachers, the positive effects of Yama and Niyama practices related to psychological changes and behaviours. We quote some frequent comments from students of their experiences in emotion and positive attitude such as: "Yama and Niyama ethics made me a happy person...more compassion to all living beings "; "I could introspect daily and this made me more satisfy with these moral values, they are very important in my life."; "...It is just like a panacea for me. Yama and Niyama practices changed my life."; "All the ethical disciplines are very special for me, it helped me to know about my inner energy and sources which can be used to replace negative thinking by positive thinking." Improvements in self-awareness also made with comments such as:" Improved lot in my mental status...more calm and relax...improved concentration in the study, creative thinking, more self-discipline and as well as will power... I become more serious toward my life." Some students noted cultivating a good relationship to family and friends such as:" I became a good listener... I started caring for others...make more friends and good companies."; "I can control my anger more easily... Family love gives me strength." It is important to note that all these comments showed the positive impact of YN intervention in line with aforesaid multiple yoga based-evidences.

\section{Limitations and Future Direction}

In the present study, several limitations should be resolved, the small and homogeneity of the present sample limit more accurate outcomes, in addition, the single assessment instrument is not able to further examine the biological and psychological mechanisms. Future studies should with larger samples, different populations and nations, with rigorous methodology including multiple assessment tools to explore yoga ethics for mental and physical health, especially in stress-related disorders. It is important to note that integrating Yama and Niyama with other limbs of yoga as a complete practice might result in more benefits in general health.

\section{Conclusion}

In summary, this current study is the first randomized control trail of yoga ethics. The results indicate that Yama and Niyama intervention might be efficacious on stress reduction and psychological well-being in college students. This finding suggests that authorities of higher education institutes adopt this cost-effective self-care strategy into the regular curriculum to modulate the high prevalence of common psychological disorders among college students. Furthermore, Yama and Niyama intervention could add to alternate and complementary medicine to release the burden of insufficient resource of outpatient mental health treatment. 


\section{Acknowledgements}

We gratefully acknowledge the support from Yogoda Satsanga Mahavidyalaya College and all cooperation from teachers and participants.

\section{References}

1) Patton GC, Coffey C, Romaniuk H, Mackinnon A, Carlin JB, Degenhardt L, et al. The prognosis of common mental disorders in adolescents: a 14-year prospective cohort study. The Lancet. 2014;383(9926):1404-1411. Available from: https://dx.doi.org/10.1016/s0140-6736(13)62116-9.

2) Auerbach RP, Mortier P, Bruffaerts R, Alonso J, Benjet C, Cuijpers P, et al. WHO WMH-ICS Collaborators. WHO world mental health surveys international college student project: prevalence and distribution of mental disorders. Journal of abnormal psychology. 2018;127(7):623-638. Available from: https://doi.org/10.1037/abn0000362.

3) Auerbach RP, Alonso J, Axinn WG, Cuijpers P, Ebert DD, Green JG, et al. Mental disorders among college students in the World Health Organization World Mental Health Surveys. Psychological Medicine. 2016;46(14):2955-2970. Available from: https://dx.doi.org/10.1017/s0033291716001665.

4) Bruffaerts R, Mortier P, Kiekens G, Auerbach RP, Cuijpers P, Demyttenaere K, et al. Mental health problems in college freshmen: Prevalence and academic functioning. Journal of Affective Disorders. 2018;225:97-103. Available from: https://dx.doi.org/10.1016/j.jad.2017.07.044.

5) Sussman S, Arnett JJ. Emerging adulthood: developmental period facilitative of the addictions. Evaluation \& the Health Professions. 2014;37(2):147-155. Available from: https://dx.doi.org/10.1177/0163278714521812.

6) Li AW, Goldsmith CA. The effects of yoga on anxiety and stress. Alternative Medicine Review: a journal of clinical therapeutic. 2012;17(1):21-35. Available from: https://pubmed.ncbi.nlm.nih.gov/22502620/.

7) Stillwell SB, Vermeesch AL, Scott JG. Interventions to Reduce Perceived Stress Among Graduate Students: A Systematic Review With Implications for Evidence-Based Practice. Worldviews on Evidence-Based Nursing. 2017;14(6):507-513. Available from: https://dx.doi.org/10.1111/wvn.12250.

8) Chung SC. Yoga and meditation in youth education: a systematic review. The Lancet. 2018;392(18):32052-32052. Available from: https://doi.org/10.1016/ s0140-6736(18)32052-x.

9) Breedvelt JJF, Amanvermez Y, Harrer M, Karyotaki E, Gilbody S, Bockting CLH, et al. The Effects of Meditation, Yoga, and Mindfulness on Depression, Anxiety, and Stress in Tertiary Education Students: A Meta-Analysis. Frontiers in Psychiatry. 2019;10:193. Available from: https://dx.doi.org/10.3389/ fpsyt.2019.00193.

10) Amanvermez Y, Rahmadiana M, Karyotaki E, Wit L, Ebert DD, Kessler RC. Stress management interventions for college students: A systematic review and meta-analysis. Clinical Psychology: Science and Practice. 2020;(e12342):1-27. Available from: https://dx.doi.org/10.1111/cpsp.12342.

11) Malathi A, Damodaran A. Stress due to exams in medical students-role of yoga. Indian Journal of Physiology and Pharmacology. 1999;43(2):218-224. Available from: https://www.ijpp.com/IJPParchives/1999_43_2/218-224.pdf.

12) Gopal A, Mondal S, Gandhi A, Arora S, Bhattacharjee J. Effect of integrated yoga practices on immune responses in examination stress - A preliminary study. International Journal of Yoga. 2011;4(1):26-32. Available from: https://dx.doi.org/10.4103/0973-6131.78178.

13) Gard T, Brach N, Hölzel BK, Noggle JJ, Conboy LA, Lazar SW. Effects of a yoga-based intervention for young adults on quality of life and perceived stress: The potential mediating roles of mindfulness and self-compassion. The Journal of Positive Psychology. 2012;7(3):165-175. Available from: https://dx.doi.org/10.1080/17439760.2012.667144.

14) Brems C. A Yoga Stress Reduction Intervention for University Faculty, Staff, and Graduate Students. International Journal of Yoga Therapy. 2015;25(1):6177. Available from: https://dx.doi.org/10.17761/1531-2054-25.1.61.

15) Sauer-Zavala SE, Walsh EC, Eisenlohr-Moul TA, Lykins ELB. Comparing Mindfulness-Based Intervention Strategies: Differential Effects of Sitting Meditation, Body Scan, and Mindful Yoga. Mindfulness. 2013;4(4):383-388. Available from: https://dx.doi.org/10.1007/s12671-012-0139-9.

16) Bond AR, Mason HF, Lemaster CM, Shaw SE, Mullin CS, Holick E, et al. Embodied health: the effects of a mind-body course for medical students. Medical Education Online. 2013;18:1-8. Available from: https://dx.doi.org/10.3402/meo.v18i0.20699.

17) Nagendra H, Kumar V, Mukherjee S. Cognitive Behavior Evaluation Based on Physiological Parameters among Young Healthy Subjects with Yoga as Intervention. Computational and Mathematical Methods in Medicine. 2015;2015:1-13. Available from: https://dx.doi.org/10.1155/2015/821061.

18) Saoji A, Mohanty S, Vinchurkar SA. Effect of a Single Session of a Yogic Meditation Technique on Cognitive Performance in Medical Students: A Randomized Crossover Trial. Journal of Religion and Health. 2017;56(1):141-148. Available from: https://dx.doi.org/10.1007/s10943-016-0195-x.

19) Sharma S, Nivethitha L, Mooventhan A. Effect of Moola Bandha (Perineum Contraction), A Yogic Lock on Cognitive Functions of College Students: An Exploratory Study. Journal of Religion and Health. 2020;59(3):1388-1397. Available from: https://dx.doi.org/10.1007/s10943-019-00856-0.

20) Bollimbala A, James PS, Ganguli S. The effect of Hatha yoga intervention on students' creative ability. Acta Psychologica. 2020;209:103-121. Available from: https://dx.doi.org/10.1016/j.actpsy.2020.103121.

21) Yogananda P. God Talks with Arjuna - The Bhagavad Gita. Ranchi. 2016.

22) Cope S. The Wisdom of Yoga. New York; Bantam. 2007.

23) Sharma VK, Trakroo M, Subramaniam V, Sahai A, Bhavanani A, Rajajeyakumar M. Effect of fast and slow pranayama on perceived stress and cardiovascular parameters in young health-care students. International Journal of Yoga. 2013;6(2):104-110. Available from: https://dx.doi.org/10.4103/0973-6131.113400.

24) Wheeler EA, Santoro AN, Bembenek AF. Separating the "limbs" of yoga: limited effects on stress and mood. Journal of Religion and Health. 2019;58(6):2277-2287. Available from: https://doi.org/10.1007/s10943-017-0482-1.

25) Patel NK, Nivethitha L, Mooventhan A. Effect of a Yoga Based Meditation Technique on Emotional Regulation, Self-compassion and Mindfulness in College Students. EXPLORE. 2018;14(6):443-447. Available from: https://dx.doi.org/10.1016/j.explore.2018.06.008.

26) Korotkov KG. The Energy of Health: Understanding Bio-Well Analysis. and others, editor;CreateSpace Independent Publishing Platform. 2017.

27) Kushwah KK, Srinivasan TM, Nagendra HR, Ilavarasu JV. Effect of yoga based techniques on stress and health indices using electro photonic imaging technique in managers. Journal of Ayurveda and Integrative Medicine. 2016;7(2):119-123. Available from: https://dx.doi.org/10.1016/j.jaim.2015.05.001.

28) Deo G, Kumar IR, Srinivasan TM, Kushwah KK. Cumulative effect of short-term and long-term meditation practice in men and women on psychophysiological parameters of electrophotonic imaging: a cross-sectional study. Journal of Complementary and Integrative Medicine. 2016;13(1):73-82. Available from: https://dx.doi.org/10.1515/jcim-2015-0050.

29) Hegde JR, Melukote SK, Vijayendra K, Singh D. A randomized study on the energy difference measured by electro photonic image on caregivers practiced Indian aesthetic dance and yoga. International Journal Of Community Medicine And Public Health. 2020;7(7):2770-2777. Available from: 
https://dx.doi.org/10.18203/2394-6040.ijcmph20203013.

30) Yogananda P. Autobiography of a Yogi. Ranchi. 2011.

31) Narayanan CR. EPI Reading of Before and After Yoga Session. 2020. Available from: http://iumab.club/assets/files/papers/Yoga/2014\%20Rajan\% 20Narayanan_EPI_Yoga\%20Session\%20.PDF.Dateaccessed:10/10/2020.

32) Gard T, Noggle JJ, Park CL, Vago DR, Wilson A. Potential self-regulatory mechanisms of yoga for psychological health. Frontiers in Human Neuroscience. 2014;8(770):1-20. Available from: https://dx.doi.org/10.3389/fnhum.2014.00770.

33) Tang YY. Mechanism of integrative body-mind training. Neuroscience Bulletin. 2011;27(6):383-388. Available from: https://doi.org/10.1007/s12264-0111141-2.

34) Riley KE, Park CL. How does yoga reduce stress? A systematic review of mechanisms of change and guide to future inquiry. Health Psychology Review. 2015;9(3):379-396. Available from: https://dx.doi.org/10.1080/17437199.2014.981778.

35) Unger CA, Busse D, Yim IS. The effect of guided relaxation on cortisol and affect: Stress reactivity as a moderator. Journal of Health Psychology. 2017;22(1):29-38. Available from: https://dx.doi.org/10.1177/1359105315595118.

36) Lemay V, Hoolahan J, Buchanan A. Impact of a Yoga and Meditation Intervention on Students' Stress and Anxiety Levels. American Journal of Pharmaceutical Education. 2019;83(5):747-752. Available from: https://dx.doi.org/10.5688/ajpe7001.

37) D A. The Yamas \& Niyamas: Exploring Yoga's Ethical Practice. 1st ed. and others, editor;On-Word Bound Books: Minnesota. 2009.

38) Karyotaki E, Cuijpers P, Albor Y, Alonso J, Auerbach RP, Bantjes J, et al. Sources of stress and their associations with mental disorders among college students: results of the world health organization world mental health surveys international college student initiative. Frontiers in Psychology;11(1759):111. Available from: https://doi.org/10.3389/fpsyg.2020.01759.

39) Eisenberg N. Emotion, regulation, and moral development. Annual Review of Psychology. 2000;51:665-697. Available from: https://doi.org/10.1146/ annurev.psych.51.1.665.

40) Bzdok D, Schilbach L, Vogeley K, Schneider K, Laird AR, Langner R, et al. Parsing the neural correlates of moral cognition: ALE meta-analysis on morality, theory of mind, and empathy. Brain Structure and Function. 2012;217(4):783-796. Available from: https://dx.doi.org/10.1007/s00429-012-0380-y. 